\title{
Differential $\beta$-catenin expression levels are associated with morphological features and prognosis of colorectal cancer
}

\author{
ZHAO-HUA GAO ${ }^{1,2,3 *}$, CHONG LU $^{1 *}$, MEI-XIAN WANG ${ }^{4}$, \\ $\mathrm{YI} \mathrm{HAN}^{2}$ and LI-JUAN GUO ${ }^{2}$ \\ ${ }^{1}$ Department of Surgical Oncology and General Surgery, First Hospital of China Medical University, Shenyang, \\ Liaoning 110001; ${ }^{2}$ Department of Surgery, Shenyang Red Cross Hospital, Shenyang, Liaoning 110013; \\ ${ }^{3}$ Department of Breast Surgery, Liaoning Province Cancer Hospital and Institute, Shenyang, Liaoning 110042; \\ ${ }^{4}$ Department of Tumor Pathology and Surgical Oncology, First Hospital of \\ China Medical University, Shenyang, Liaoning 110001; P.R. China
}

Received December 6, 2013; Accepted July 18, 2014

DOI: $10.3892 / \mathrm{ol} .2014 .2433$

\begin{abstract}
. $\beta$-catenin, an epithelial-mesenchymal transition (EMT)-associated marker, is key in the progression of colorectal cancer (CRC). However, the prognostic significance of $\beta$-catenin expression in patients with $\mathrm{CRC}$ remains controversial. In the present study, the expression of $\beta$-catenin at the tumor invasive front and the tumor center was investigated, and the correlations amongst $\beta$-catenin differential expression patterns and the clinicopathological characteristics and prognosis of CRC patients were determined. In total, 181 patients that were diagnosed with CRC (as determined by histopathological evaluation) and subjected to surgical resection at the First Hospital of China Medical University between 2000 and 2001 were examined, and CRC specimens were obtained. Immunohistochemical (IHC) staining of $\beta$-catenin was performed for each specimen. The nuclear $\beta$-catenin expression levels were identified to be significantly lower in the tumor center than at the tumor invasive front (immunoreactivity score, $0.05 \pm 0.303$ versus $2.18 \pm 3.917$; $\mathrm{P}<0.001)$. The presence of nuclear $\beta$-catenin overexpression at the tumor invasive front was found to be correlated with the tumor, node, metastasis stage $(\mathrm{P}=0.020)$, lymph node metastasis $(\mathrm{P}=0.016)$ and histological differentiation $(\mathrm{P}=0.006)$. Survival analysis revealed that reduced membranous expression levels and increased nuclear expression levels of $\beta$-catenin were statistically significantly associated with poor survival times. Furthermore,
\end{abstract}

Correspondence to: Dr Chong Lu, Department of Surgical Oncology and General Surgery, First Hospital of China Medical University, 155 North Nanjing Street, Shenyang, Liaoning 110001, P.R. China

E-mail: gaozhaohua6@sina.com

${ }^{*}$ Contributed equally

Key words: $\beta$-catenin, colorectal cancer, epithelial-mesenchymal transition, tumor budding, invasive front differential $\beta$-catenin expression levels were associated with aggressive morphological features, EMT and a poor prognosis in CRC. Therefore, IHC analysis of $\beta$-catenin is considered to be a useful marker to predict the prognosis in patients with CRC.

\section{Introduction}

Colorectal cancer (CRC) is the second most common cause of cancer-associated mortality worldwide. Overall, $~ 50 \%$ of patients diagnosed with CRC succumb to the disease, due to complications associated with distant metastasis (1). The incidence of CRC in China has increased over recent years, particularly in the more developed areas (2). The tumor-host interaction at the invasive margin of $\mathrm{CRC}$ is a crucial interface where tumor progression and tumor cell dissemination ensue (3). Epithelial-mesenchymal transition (EMT), a dynamic process of colorectal carcinoma cell dedifferentiation, occurs at the invasive tumor front (4). The biological behavior of cancer is considered to be more accurately reflected by the histologic features present at the invasive front rather than those observed at the tumor center.

$\beta$-catenin is a component of the Wingless/Wnt signaling pathway. Dysfunction of the Wnt signaling pathway is important in colorectal carcinogenesis and results in the nuclear accumulation of $\beta$-catenin (5). Membranous beta-catenin forms a complex with E-cadherin, a critical mediator of cell-cell adhesion, and is responsible for the maintenance of cell polarity (6). The membranous expression of beta-catenin and E-cadherin characterizes the epithelial phenotype whereas the loss of this membranous expression is indicative of a switch toward a more mesenchymal phenotype. The nuclear translocation of $\beta$-catenin induces EMT and pro-invasive gene expression (7). Therefore, the differential intracellular distribution of $\beta$-catenin exerts a marked impact on the phenotype and behavior of tumor cells (8).

In the present study, the expression of the EMT-associated marker, $\beta$-catenin at the tumor invasive front and tumor center was investigated using immunohistochemical (IHC) analysis, and the correlations among $\beta$-catenin differential expression patterns, and clinicopathological characteristics and prognosis in CRC cases were determined. 


\section{Materials and methods}

Patients and specimens. A total of 181 CRC tissue samples were obtained from patients diagnosed with CRC (as determined by histopathological evaluation) and subjected to surgical resection at the First Hospital of China Medical University (Shenyang, China) between 2000 and 2001. None of the patients had been treated with preoperative chemotherapy or radiation. Two senior pathologists reviewed the tissue sections from all of the cases. Tumor histological classification was assessed according to the World Health Organization criteria (9) and classified using the seventh edition of the tumor, node, metastasis (TNM) staging manual produced by the International Union Against Cancer/American Joint Committee on Cancer (2010) (10). All patients were followed up via telephone enquiry or questionnaire. The follow-up time ranged between 1.5 and 71 months (median, 51 months). The Ethics Committee of China Medical University approved the use of tissue samples in this study. Written informed consent was obtained from all of the patients.

Antibodies and reagents. The primary antibodies used were monoclonal rabbit anti-human $\beta$-catenin (Abcam, Cambridge, UK).

Immunohistochemistry. Formalin-fixed, paraffin-embedded sections (4- $\mu \mathrm{m}$ thick) were prepared from the CRC samples. The tissue sections were deparaffinized and rehydrated via sequential washing with xylene, graded ethanol and phosphate-buffered saline (PBS). Following deparaffinization and rehydration, the tissue sections were subjected to high temperature-induced epitope retrieval by briefly steaming in target retrieval solution $(10 \mathrm{mM}$ citrate buffer; $\mathrm{pH} 6.0$; (Beijing Zhongshan Golden Bridge Biotechnology Co., Ltd., Beijing, China). Subsequently, the sections were treated with normal goat serum blocking solution (Beijing Zhongshan Golden Bridge Biotechnology Co., Ltd.) and then incubated with $\beta$-catenin primary antibody (dilution, 1:500) overnight at $4^{\circ} \mathrm{C}$. Antibody binding was detected using an SP reagent kit (Zhongshan Chemical, Beijing, China) following the manufacturer's instructions. PBS replaced the primary antibody in the negative control and samples that were known to express $\beta$-catenin served as the positive controls. All sections were counterstained with hematoxylin, dehydrated and mounted.

Evaluation of staining. The degree of IHC staining in the tissue sections was scored independently by two pathologists who were blinded to the clinical and pathological data. Staining intensity was graded using a scale of 0-3 as follows: 0 , No staining; 1 , weak staining; 2 , moderate staining; and 3 , strong staining (11). The extent of staining was graded on a scale as follows: $0, \leq 5 \% ; 1,6-25 \% ; 2,26-50 \% ; 3,51-75 \%$; or 4 , $76-100 \%$ according to the percentage of the section exhibiting positive staining, relative to the entire carcinoma-involved area $(12,13)$. The intensity and extent scores were multiplied to generate the immunoreactivity score (IS; range, $0-12$ ) for each case $(12,13) . \beta$-catenin immunoreactivity was separately analyzed for the tumor center and the tumor invasive front. Specimens were rescored if there were discrepancies in the IS obtained by the two pathologists, until a consensus was reached.
Table I. Paired sample comparison (t-test) of $\beta$-catenin expression levels between the tumor center and tumor invasive front.

\begin{tabular}{llcc}
\hline & \multicolumn{3}{c}{ Immunoreactivity score } \\
\cline { 2 - 4 } Variable & No. & Mean \pm SD & P-value \\
\hline Membranous $\beta$-catenin & & & \\
$\quad$ Tumor center & 181 & $5.36 \pm 3.812$ & $<0.001$ \\
$\quad$ Tumor front & 181 & $0.42 \pm 1.252$ & \\
$\quad$ Nuclear $\beta$-catenin & & & \\
$\quad$ Tumor center & 181 & $0.05 \pm 0.303$ & $<0.001$ \\
$\quad$ Tumor front & 181 & $2.18 \pm 3.917$ & \\
\hline
\end{tabular}

$\mathrm{P}<0.05$ indicates a significant difference. $\mathrm{SD}$, standard deviation.

Membranous expression of $\beta$-catenin was classified as preserved when $>80 \%$ of the cell membrane was stained; otherwise, the sample was classified as exhibiting reduced expression (14). High cytoplasmic and nuclear $\beta$-catenin expression grades were defined as $>50 \%$ reactivity of the tumor cells (15).

Statistical analysis. Statistical analysis was performed using SPSS software (version 17.0; SPSS, Inc., Chicago, IL, USA). The paired-samples t-test was used to compare the differential $\beta$-catenin expression levels between the tumor center and the tumor invasive front. The statistical significance of the associations between $\beta$-catenin expression levels and the patient clinicopathological parameters was assessed using $\chi^{2}$ tests. Kaplan-Meier survival curves were plotted to analyze the distribution of CRC-specific survival times and intergroup differences were determined using the log-rank test. A multivariate Cox regression model through a stepwise selection procedure was applied to examine the independence of the significant factors identified in the univariate analysis. Cox proportional hazards regression was used to calculate the mortality hazard ratios according to various clinicopathological features and protein markers. Two-sided $\mathrm{P}<0.05$ was considered to indicate a statistically significant difference.

\section{Results}

Expression of $\beta$-catenin in CRC. $\beta$-catenin protein expression was evaluated in the CRC sections via IHC analysis. As shown in Fig. 1, $\beta$-catenin staining was observed predominantly at the cell membrane, and marginally in the cell cytoplasm and nucleus. Membranous $\beta$-catenin expression was identified to be significantly higher in the tumor center than at the tumor invasive front (IS: $5.36 \pm 3.812$ versus $0.42 \pm 1.252$, respectively; $\mathrm{P}<0.001)$. However, reduced membranous $\beta$-catenin expression levels in the tumor center were identified in 107 (59.1\%) of the 181 patients. Nuclear $\beta$-catenin expression levels were significantly lower at the tumor center than at the tumor invasive front (IS: $0.05 \pm 0.303$ versus $2.18 \pm 3.917$, respectively; $\mathrm{P}<0.001)$ as shown in Fig. 2 and Table I. High nuclear $\beta$-catenin expression levels at the tumor invasive front were observed in $30(16.6 \%)$ of the 181 patients. 
Table II. $\beta$-catenin expression levels at the tumor center in association with patient clinicopathological variables.

\begin{tabular}{|c|c|c|c|c|c|c|c|c|c|c|}
\hline \multirow[b]{2}{*}{ Variable } & \multirow[b]{2}{*}{ Total } & \multicolumn{3}{|c|}{$\begin{array}{c}\text { Membranous } \\
\text { expression levels }\end{array}$} & \multicolumn{3}{|c|}{$\begin{array}{c}\text { Cytoplasmic } \\
\text { expression levels }\end{array}$} & \multicolumn{3}{|c|}{$\begin{array}{c}\text { Nuclear } \\
\text { expression levels }\end{array}$} \\
\hline & & Preserved & Reduced & P-value & Low & High & P-value & Low & High & P-value \\
\hline \multicolumn{11}{|l|}{ Age (years) } \\
\hline$\leq 60$ & 65 & 21 & 44 & 0.079 & 47 & 18 & 0.248 & 62 & 3 & 0.255 \\
\hline$>60$ & 116 & 53 & 63 & & 92 & 24 & & 114 & 2 & \\
\hline \multicolumn{11}{|l|}{ Gender } \\
\hline Male & 105 & 43 & 62 & 0.982 & 82 & 23 & 0.626 & 103 & 2 & 0.408 \\
\hline Female & 76 & 31 & 45 & & 57 & 19 & & 73 & 3 & \\
\hline \multicolumn{11}{|c|}{ Tumor size $(\mathrm{cm})$} \\
\hline$\leq 5$ & 94 & 40 & 54 & 0.635 & 71 & 23 & 0.675 & 91 & 3 & 0.714 \\
\hline$>5$ & 87 & 34 & 53 & & 68 & 19 & & 85 & 2 & \\
\hline \multicolumn{11}{|l|}{ Tumor site } \\
\hline Colon & 72 & 27 & 45 & 0.425 & 59 & 13 & 0.182 & 69 & 3 & 0.349 \\
\hline Rectum & 109 & 47 & 62 & & 80 & 29 & & 107 & 2 & \\
\hline \multicolumn{11}{|l|}{ T stage } \\
\hline pT1-pT2 & 61 & 30 & 31 & 0.106 & 52 & 9 & 0.055 & 60 & 1 & 0.511 \\
\hline pT3-pT4 & 120 & 44 & 76 & & 87 & 33 & & 116 & 4 & \\
\hline \multicolumn{11}{|l|}{$\mathrm{N}$ stage } \\
\hline $\mathrm{pN} 0$ & 108 & 54 & 54 & $0.002^{\mathrm{a}}$ & 88 & 20 & 0.069 & 104 & 4 & 0.347 \\
\hline pN1-pN2 & 73 & 20 & 53 & & 51 & 22 & & 72 & 1 & \\
\hline \multicolumn{11}{|l|}{ TNM stage } \\
\hline I-II & 107 & 54 & 53 & $0.002^{\mathrm{a}}$ & 87 & 20 & 0.084 & 103 & 4 & 0.335 \\
\hline III-IV & 74 & 20 & 54 & & 52 & 22 & & 73 & 1 & \\
\hline \multicolumn{11}{|c|}{ Tumor deposit } \\
\hline Absent & 152 & 65 & 87 & 0.239 & 117 & 35 & 0.897 & 147 & 5 & 0.322 \\
\hline Present & 29 & 9 & 20 & & 22 & 7 & & 29 & 0 & \\
\hline \multicolumn{11}{|c|}{ Differentiation } \\
\hline Well, mod & 132 & 57 & 75 & 0.302 & 98 & 34 & 0.182 & 127 & 5 & 0.167 \\
\hline Por, muc & 49 & 17 & 32 & & 41 & 8 & & 49 & 0 & \\
\hline \multicolumn{11}{|c|}{ Lymph invasion } \\
\hline Negative & 167 & 70 & 97 & 0.329 & 128 & 39 & 0.870 & 162 & 5 & 0.511 \\
\hline Positive & 14 & 4 & 10 & & 11 & 3 & & 14 & 0 & \\
\hline \multicolumn{11}{|c|}{ Venous invasion } \\
\hline Negative & 178 & 73 & 105 & 0.789 & 136 & 42 & 0.337 & 173 & 5 & 0.768 \\
\hline Positive & 3 & 1 & 2 & & 3 & 0 & & 3 & 0 & \\
\hline
\end{tabular}

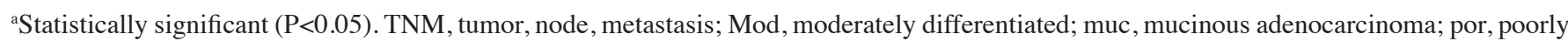
differentiated and undifferentiated.

Correlation between $\beta$-catenin expression levels and the clinicopathological characteristics of $C R C$. The reduced membranous $\beta$-catenin expression levels at the tumor center were identified to be significantly associated with the occurrence of lymph node metastasis $(\mathrm{P}=0.002)$ and the TNM stage $(\mathrm{P}=0.002)$. However, no associations between reduced membranous $\beta$-catenin expression levels and age/gender at diagnosis, tumor site or size, invasion depth, presence or absence of tumor deposits, histological differentiation, or lymphatic or venous invasion were evident. In addition, no statistically significant correlations between cytoplasmic or nuclear expression levels of $\beta$-catenin and the above-mentioned clinicopathological characteristics were observed (Table II).

At the tumor invasive front, the detection of high nuclear expression levels of $\beta$-catenin was significantly correlated with lymph node metastasis $(\mathrm{P}=0.016)$, the TNM stage $(\mathrm{P}=0.020)$ and histological differentiation $(\mathrm{P}=0.006)$, however, not with age/gender at diagnosis, tumor site or size, invasion depth, presence or absence of tumor deposits, or lymphatic or venous 
Table III. $\beta$-catenin expression levels at the tumor invasive front in association with patient clinicopathological variables.

\begin{tabular}{|c|c|c|c|c|c|c|c|c|c|c|}
\hline \multirow[b]{2}{*}{ Variable } & \multirow[b]{2}{*}{ Total } & \multicolumn{3}{|c|}{$\begin{array}{c}\text { Membranous } \\
\text { expression levels }\end{array}$} & \multicolumn{3}{|c|}{$\begin{array}{c}\text { Cytoplasmic } \\
\text { expression levels }\end{array}$} & \multicolumn{3}{|c|}{$\begin{array}{c}\text { Nuclear } \\
\text { expression levels }\end{array}$} \\
\hline & & Reduced & Preserved & P-value & Low & High & P-value & Low & High & P-value \\
\hline \multicolumn{11}{|l|}{ Age (years) } \\
\hline$\leq 60$ & 65 & 52 & 13 & 0.151 & 37 & 28 & 0.080 & 57 & 8 & 0.248 \\
\hline$>60$ & 116 & 102 & 14 & & 81 & 35 & & 94 & 22 & \\
\hline \multicolumn{11}{|l|}{ Gender } \\
\hline Male & 105 & 91 & 14 & 0.482 & 66 & 39 & 0.438 & 90 & 15 & 0.330 \\
\hline Female & 76 & 63 & 13 & & 52 & 24 & & 61 & 15 & \\
\hline \multicolumn{11}{|c|}{ Tumor size $(\mathrm{cm})$} \\
\hline$\leq 5$ & 94 & 83 & 11 & 0.207 & 60 & 34 & 0.689 & 76 & 18 & 0.333 \\
\hline$>5$ & 87 & 71 & 16 & & 58 & 29 & & 75 & 12 & \\
\hline \multicolumn{11}{|l|}{ Tumor site } \\
\hline Colon & 72 & 58 & 14 & 0.165 & 56 & 16 & $0.004^{\mathrm{a}}$ & 62 & 10 & 0.430 \\
\hline Rectum & 109 & 96 & 13 & & 62 & 47 & & 89 & 20 & \\
\hline \multicolumn{11}{|l|}{ T stage } \\
\hline pT1-pT2 & 61 & 54 & 7 & 0.354 & 40 & 21 & 0.939 & 54 & 7 & 0.188 \\
\hline pT3-pT4 & 120 & 100 & 20 & & 78 & 42 & & 97 & 23 & \\
\hline \multicolumn{11}{|l|}{$\mathrm{N}$ stage } \\
\hline $\mathrm{pN} 0$ & 108 & 91 & 17 & 0.705 & 73 & 35 & 0.410 & 96 & 12 & $0.016^{\mathrm{a}}$ \\
\hline pN1-pN2 & 73 & 63 & 10 & & 45 & 28 & & 55 & 18 & \\
\hline \multicolumn{11}{|l|}{ TNM stage } \\
\hline I-II & 107 & 90 & 17 & 0.659 & 72 & 35 & 0.476 & 95 & 12 & $0.020^{\mathrm{a}}$ \\
\hline III-IV & 74 & 64 & 10 & & 46 & 28 & & 56 & 18 & \\
\hline \multicolumn{11}{|c|}{ Tumor deposit } \\
\hline Absent & 152 & 130 & 22 & 0.701 & 99 & 53 & 0.968 & 129 & 23 & 0.232 \\
\hline Present & 29 & 24 & 5 & & 19 & 10 & & 22 & 7 & \\
\hline \multicolumn{11}{|c|}{ Differentiation } \\
\hline Well, mod & 132 & 109 & 23 & 0.120 & 77 & 55 & $0.001^{\mathrm{a}}$ & 104 & 28 & $0.006^{\mathrm{a}}$ \\
\hline Por, muc & 49 & 45 & 4 & & 41 & 8 & & 47 & 2 & \\
\hline \multicolumn{11}{|c|}{ Lymph invasion } \\
\hline Negative & 167 & 143 & 24 & 0.476 & 110 & 57 & 0.510 & 139 & 28 & 0.811 \\
\hline Positive & 14 & 11 & 3 & & 8 & 6 & & 12 & 2 & \\
\hline \multicolumn{11}{|c|}{ Venous invasion } \\
\hline Negative & 178 & 151 & 27 & 0.465 & 116 & 62 & 0.957 & 148 & 30 & 0.436 \\
\hline Positive & 3 & 3 & 0 & & 2 & 1 & & 3 & 0 & \\
\hline
\end{tabular}

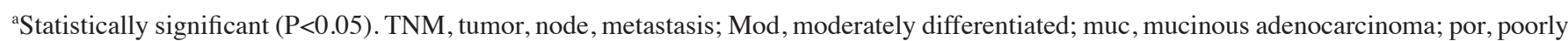
differentiated and undifferentiated.

invasion. In addition, high cytoplasmic expression levels of $\beta$-catenin were significantly correlated with histological differentiation $(\mathrm{P}=0.001)$ and tumor site $(\mathrm{P}=0.004)$. No statistically significant association was observed between the presence of high cytoplasmic expression of $\beta$-catenin and age/gender at diagnosis, tumor size, invasion depth, lymph node metastasis, TNM stage, presence or absence of tumor deposits, or lymphatic or venous invasion. Furthermore, no statistically significant correlation was detected between the detection of reduced membranous expression levels of $\beta$-catenin and the above-mentioned clinicopathological characteristics (Table III).

Survival analysis. Patients with reduced membranous expression levels of $\beta$-catenin at the tumor center had significantly lower cancer-specific five-year survival rates $(58.5 \%)$, compared with patients that exhibited preserved membranous expression of $\beta$-catenin at the tumor center $(78.1 \%$; log-rank, $\mathrm{P}=0.028$; Fig. $3 \mathrm{~A}$ ). The difference in cancer-specific survival rates between patients with high-grade nuclear expression 

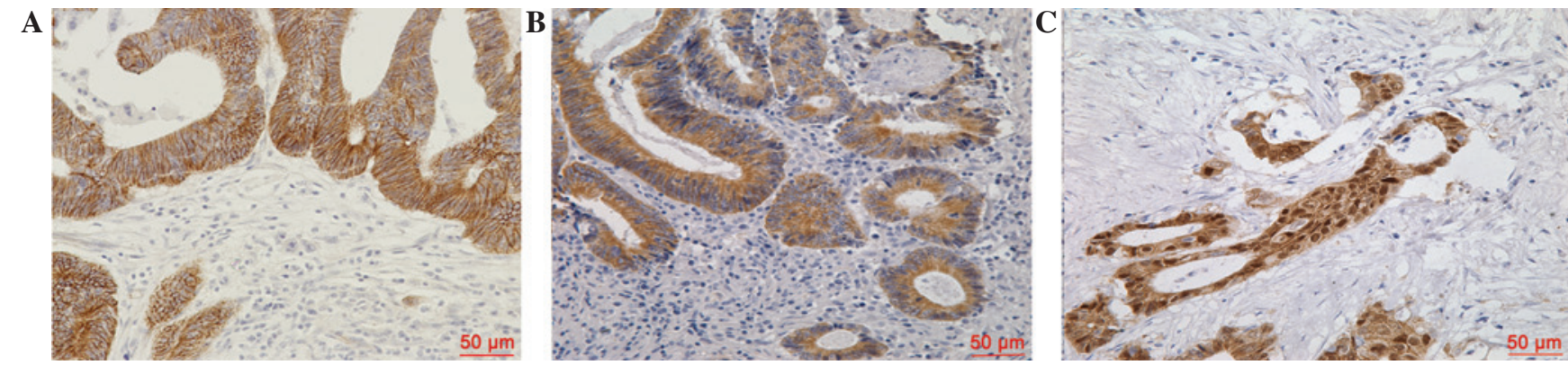

Figure 1. Immunohistochemical staining of $\beta$-catenin in colorectal cancer samples. (A) $\beta$-catenin membranous expression. (B) $\beta$-catenin cytoplasmic expression. (C) $\beta$-catenin nuclear expression.

Tumor center

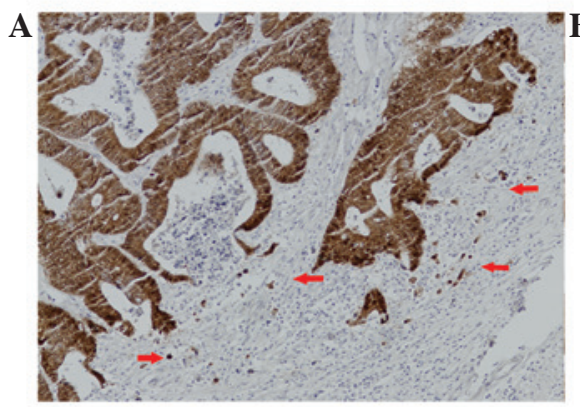

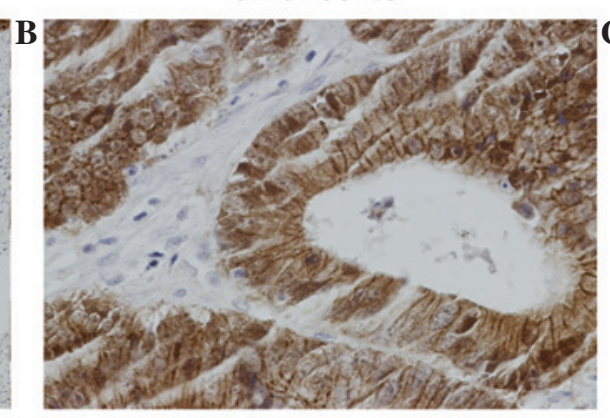

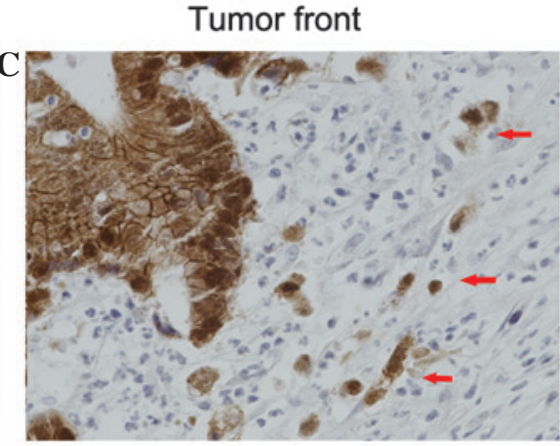

Figure 2. Immunohistochemical staining demonstrating differential $\beta$-catenin expression levels at the tumor center and at the tumor invasive front. (A) Overview picture demonstrating both the tumor center and the tumor invasive front. The red arrows indicate tumor budding and nuclear $\beta$-catenin expression. (magnification, $\mathrm{x} 200$ ). (B) At the tumor center, $\beta$-catenin expression was predominant at the cell membrane. (C) At the tumor invasive front, the red arrows indicate that the isolated single tumor cells or the small clusters of tumor cells (tumor budding) had scattered from the primary mass with marked nuclear $\beta$-catenin accumulation (epithelial-mesenchymal transition phenotype; magnification, $\mathrm{x} 400$ ).

A

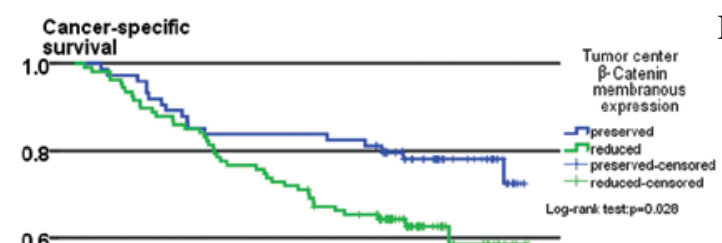

0.4

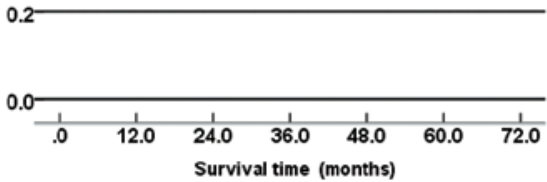

B

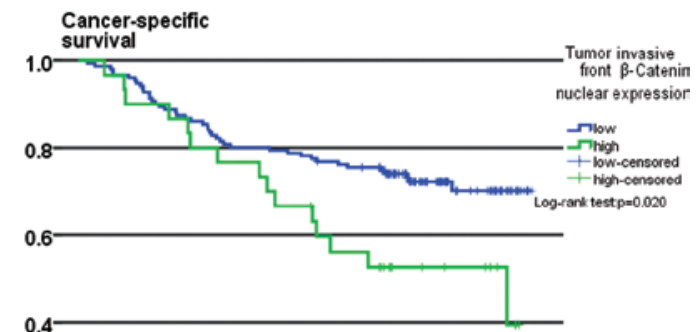

$0.2-$

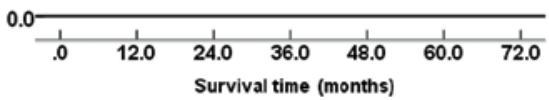

Figure 3. Kaplan-Meier survival analysis. (A) $\beta$-catenin membranous expression at the tumor center; preserved membranous expression vs. reduced membranous expression $(\mathrm{P}=0.028)$. (B) $\beta$-catenin nuclear expression at the tumor invasive front; low vs. high expression levels $(\mathrm{P}=0.020)$.

of $\beta$-catenin (five-year survival rate, $52.6 \%$ ) and low-grade nuclear expression of $\beta$-catenin (five-year survival rate, $70.1 \%$ ) at the tumor invasive front was also identified to be statistically significant (log-rank test, $\mathrm{P}=0.020$; Fig. 3B).

Univariate analysis revealed that the $\mathrm{T}$ stage $(\mathrm{P}<0.001)$, $\mathrm{N}$ stage $(\mathrm{P}<0.001)$, TNM stage $(\mathrm{P}<0.001)$, the presence of lymphatic invasion $(\mathrm{P}<0.001)$, the presence of tumor deposits $(\mathrm{P}<0.001)$, reduced membranous expression levels of $\beta$-catenin at the tumor center $(\mathrm{P}=0.028)$ and high-grade nuclear expression of $\beta$-catenin at the tumor invasive front $(\mathrm{P}=0.020)$ were significant prognostic factors. However, age, gender, tumor location and size, tumor differentiation and venous invasion were not significantly associated with patient survival (Table IV).

Multivariate analysis using Cox regression analysis demonstrated that the TNM stage $(\mathrm{P}<0.001)$, presence of tumor deposits $(\mathrm{P}=0.001)$ and lymph node metastasis $(\mathrm{P}=0.026)$ were independent prognostic factors in CRC 
Table IV. Univariate and multivariate analyses of survival rates in colorectal cancer patients.

\begin{tabular}{|c|c|c|c|c|c|c|}
\hline \multirow[b]{2}{*}{ Variable } & \multirow[b]{2}{*}{$\begin{array}{l}\text { Patients } \\
\text { (n) }\end{array}$} & \multicolumn{2}{|c|}{ Univariate analysis } & \multicolumn{3}{|c|}{ Multivariate analysis } \\
\hline & & $\begin{array}{c}\text { Five-year survival } \\
\text { rate }(\%)\end{array}$ & P-value & HR & $\begin{array}{c}95 \% \\
\mathrm{CI}\end{array}$ & P-value \\
\hline \multicolumn{7}{|l|}{ Age (years) } \\
\hline$\leq 60$ & 65 & 69.7 & 0.254 & & & \\
\hline$>60$ & 116 & 66.0 & & & & \\
\hline \multicolumn{7}{|l|}{ Gender } \\
\hline Male & 105 & 69.9 & 0.151 & & & \\
\hline Female & 76 & 64.0 & & & & \\
\hline \multicolumn{7}{|c|}{ Tumor size (cm) } \\
\hline$\leq 5$ & 94 & 64.2 & 0.814 & & & \\
\hline$>5$ & 87 & 70.6 & & & & \\
\hline \multicolumn{7}{|l|}{ Tumor site } \\
\hline Colon & 72 & 65.2 & 0.266 & & & \\
\hline Rectum & 109 & 68.3 & & & & \\
\hline \multicolumn{7}{|l|}{ T stage } \\
\hline pT1-pT2 & 61 & 85.7 & $<0.001^{\mathrm{a}}$ & & & \\
\hline pT3-pT4 & 120 & 58.5 & & & & \\
\hline \multicolumn{7}{|l|}{$\mathrm{N}$ stage } \\
\hline pNO & 108 & 92.5 & $<0.001^{\mathrm{a}}$ & 10.729 & $1.336-86.14$ & $0.026^{\mathrm{a}}$ \\
\hline $\mathrm{pN} 1-\mathrm{pN} 2$ & 73 & 32.3 & & & & \\
\hline \multicolumn{7}{|l|}{ TNM stage } \\
\hline I-II & 107 & 93.4 & $<0.001^{\mathrm{a}}$ & 0.009 & $0.001-0.082$ & $<0.001^{\mathrm{a}}$ \\
\hline III-IV & 74 & 31.8 & & & & \\
\hline \multicolumn{7}{|c|}{ Tumor deposit } \\
\hline Absent & 152 & 76.8 & $<0.001^{\mathrm{a}}$ & 0.368 & $0.208-0.651$ & $0.001^{\mathrm{a}}$ \\
\hline Present & 29 & 17.2 & & & & \\
\hline \multicolumn{7}{|c|}{ Differentiation } \\
\hline Well, mod & 132 & 68.7 & 0.984 & & & \\
\hline Por, muc & 49 & 62.8 & & & & \\
\hline \multicolumn{7}{|c|}{ Lymph invasion } \\
\hline Negative & 167 & 70.1 & $<0.001^{\mathrm{a}}$ & & & \\
\hline Positive & 14 & 35.7 & & & & \\
\hline \multicolumn{7}{|c|}{ Venous invasion } \\
\hline Negative & 178 & 67.9 & 0.086 & & & \\
\hline Positive & 3 & 33.3 & & & & \\
\hline \multicolumn{7}{|c|}{ Tumor center membranous $\beta$-catenin } \\
\hline Preserved & 74 & 78.1 & $0.028^{\mathrm{a}}$ & 1.132 & $0.627-2.046$ & 0.681 \\
\hline Reduced & 107 & 58.5 & & & & \\
\hline \multicolumn{7}{|c|}{ Tumor front nuclear $\beta$-catenin } \\
\hline Low-grade & 151 & 70.1 & $0.020^{\mathrm{a}}$ & 0.708 & $0.384-1.705$ & 0.268 \\
\hline High-grade & 30 & 52.6 & & & & \\
\hline
\end{tabular}

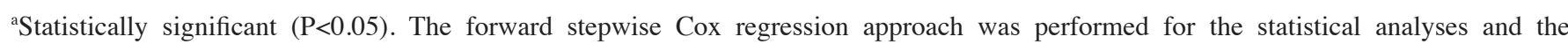
non-significant variables are not presented in the final table. CI, confidence interval; HR, hazard ratio; TNM, tumor, node, metastasis; mod, moderately differentiated; muc, mucinous adenocarcinoma; por, poorly differentiated and undifferentiated.

patients (Table IV). In addition, multivariate analysis revealed that $\beta$-catenin levels were not a significant prognostic factor.

\section{Discussion}

Despite significant advancements in CRC diagnosis and 
treatment, the prognosis for patients with advanced CRC remains poor. EMT, the switch from the polarized epithelial cell phenotype to a migratory mesenchymal phenotype, is increasingly recognized as a central event during malignant tumor progression and metastasis $(16,17)$. $\beta$-catenin maintains cell-to-cell adhesion along with E-cadherin. However, $\beta$-catenin also acts as a transcription factor in the Wnt signal transduction pathway (5). The dual role of $\beta$-catenin in cadherin-mediated cell-cell adhesion and in Wnt signaling, where it is a key effector, renders $\beta$-catenin an ideal target for analyzing the molecular basis of EMT and malignant cancer formation. The accumulation and aberrant activation of $\beta$-catenin signaling, as well as the transcription of target genes (hypothesized to contribute to various stages in tumor development) result from mutations in the adenomatous polyposis coli protein that abolish its capacity to bind $\beta$-catenin or mutations in the $\beta$-catenin phosphorylation motif at the $\mathrm{N}$-terminus. The target genes include predominant regulators of EMT, for example Slug (18), which inhibits E-cadherin transcription. The release of $\beta$-catenin from cell-cell junctions following the dismantling of cell-cell adhesions, which contain E-cadherin, during EMT and the consequent activation of $\beta$-catenin-mediated transactivation are also important in EMT regulation (19).

However, the prognostic significance of $\beta$-catenin expression levels in patients with CRC remains controversial. Certain studies have shown that nuclear $\beta$-catenin expression is associated with high tumor budding and a poor prognosis $(15,20,21)$, however, other studies did not detect this association (22-24). Additionally, a recent study revealed that $\beta$-catenin overexpression was correlated with a favorable prognosis (25).

Therefore, in the present study, the expression levels of the EMT-associated marker, $\beta$-catenin were investigated at the tumor invasive front and in the tumor center of CRC tissue specimens. Long-term clinical follow-up of the CRC patients was conducted and a large number of cases were included in the study, thus, the results are considered to be meaningful.

The levels of $\beta$-catenin protein expression in serial paraffin-embedded sections obtained from 181 human CRC samples were examined using IHC staining. The correlations between the $\beta$-catenin differential expression patterns and clinicopathological characteristics and prognosis were also assessed. The results showed that membranous $\beta$-catenin expression levels in the samples were significantly reduced at the tumor invasive front, compared with in the tumor center; however, nuclear $\beta$-catenin expression levels were significantly increased at the tumor invasive front, compared with in the tumor center. The dynamic changes in the intracellular distribution of $\beta$-catenin and the changes in tumor cell phenotype revealed a process that is reminiscent of EMT. The presence of reduced membranous expression levels of $\beta$-catenin at the tumor center was significantly associated with lymph node metastasis and the TNM stage. At the tumor invasive front, high-grade nuclear expression of $\beta$-catenin was significantly correlated with lymph node metastasis, TNM stage and histological differentiation.

Further analysis demonstrated that patients with reduced membranous expression levels of $\beta$-catenin had significantly lower cancer-specific five-year survival rates, compared with those patients exhibiting preserved membranous expression of $\beta$-catenin at the tumor center. The five-year survival rate of patients with high-grade nuclear $\beta$-catenin expression was significantly lower than that of patients with low-grade nuclear expression of $\beta$-catenin at the tumor invasive front. However, this did not persist as an independent prognostic factor following Cox multivariate analysis. The undifferentiated tumor cells at the tumor invasive front may undergo $\beta$-catenin-mediated EMT, which may result in the dissemination of tumor cells, and subsequently induce tumor invasion and metastasis.

In conclusion, the results of the present study indicate that changes in $\beta$-catenin expression levels are associated with aggressive morphological features, EMT and a poor prognosis in patients with CRC. IHC staining of $\beta$-catenin is considered to be a useful marker to predict the prognosis in CRC. However, large, well-designed prospective studies are required to further investigate the accurate prognostic significance of $\beta$-catenin.

\section{Acknowledgements}

The authors would like to thank the department of Surgical Oncology of the First Hospital of China Medical University (Shenyang, China) for providing the human colorectal cancer tissue samples and the College of China Medical University (Shenyang, China) for technical assistance during the experimental procedures.

\section{References}

1. de Krijger I, Mekenkamp LJ, Punt CJ and Nagtegaal ID: MicroRNAs in colorectal cancer metastasis. J Pathol 224: 438-447, 2011.

2. Xu AG, Yu ZJ, Jiang B, et al: Colorectal cancer in Guangdong Province of China: a demographic and anatomic survey. World J Gastroenterol 16: 960-965, 2010.

3. Zlobec I and Lugli A: Invasive front of colorectal cancer: dynamic interface of pro-/anti-tumor factors. World J Gastroenterol 15: 5898-5906, 2009.

4. Natalwala A, Spychal R and Tselepis C: Epithelial-mesenchymal transition mediated tumourigenesis in the gastrointestinal tract. World J Gastroenterol 14: 3792-3797, 2008.

5. Brabletz T, Jung A, Hermann K, et al: Nuclear overexpression of the oncoprotein beta-catenin in colorectal cancer is localized predominantly at the invasion front. Pathol Res Pract 194: 701-704, 1998

6. Guarino M,Rubino B and Ballabio G: The role of epithelial-mesenchymal transition in cancer pathology. Pathology 39: 305-318, 2007.

7. Sánchez-Tilló E, de Barrios O, Siles L, Cuatrecasas M, Castells A and Postigo A: Beta-catenin/TCF4 complex induces the epithelial-to-mesenchymal transition (EMT)-activator ZEB1 to regulate tumor invasiveness. Proc Natl Acad Sci USA 108: 19204-19209, 2011.

8. Jang TJ: Expression of E-cadherin and $\beta$-catenin is altered at tumor budding sites, whose number is associated with the progression of colorectal carcinoma. Korean J Pathol 43: 523-527, 2009.

9. International Agency for Research on Cancer: World Health Organization classification of tumours. Pathology and genetics of tumours of the digestive system. IARC Press, Lyon, France, 2000.

10. Edge SBD and Compton C. AJCC Cancer Staging Manual. 7th edition. JAMA 304: 1726-1727, 2010.

11. Ru GQ, Wang HJ, Xu WJ and Zhao ZS: Upregulation of Twist in gastric carcinoma associated with tumor invasion and poor prognosis. Pathol Oncol Res 17: 341-347, 2011.

12. Sinicrope FA, Ruan SB, Cleary KR, et al: bcl-2 and p53 oncoprotein expression during colorectal tumorigenesis. Cancer Res 55: 237-241, 1995.

13. Zhu JL, Song YX, Wang ZN, et al: The clinical significance of mesenchyme forkhead 1 (FoxC2) in gastric carcinoma. Histopathology 62: 1038-1048, 2013 
14. Boo YJ, Park JM, Kim J, et al: L1 expression as a marker for poor prognosis, tumor progression, and short survival in patients with colorectal cancer. Ann Surg Oncol 14: 1703-1711, 2007.

15. Baldus SE, Mönig SP, Huxel S, et al: MUC1 and nuclear beta-catenin are coexpressed at the invasion front of colorectal carcinomas and are both correlated with tumor prognosis. Clin Cancer Res 10: 2790-2796, 2004.

16. Grünert S, Jechlinger $M$ and Beug $H$ : Diverse cellular and molecular mechanisms contribute to epithelial plasticity and metastasis. Nat Rev Mol Cell Biol 4: 657-665, 2003.

17. Hugo H, Ackland ML, Blick T, et al: Epithelial-mesenchymal and mesenchymal-epithelial transitions in carcinoma progression. J Cell Physiol 213: 374-383, 2007.

18. Conacci-Sorrell M, Simcha I, Ben-Yedidia T, et al: Autoregulation of E-cadherin expression by cadherin-cadherin interactions: the roles of beta-catenin signaling, Slug, and MAPK. J Cell Biol 163: $847-857,2003$

19. Gavert N and Ben-Ze'ev A: Epithelial-mesenchymal transition and the invasive potential of tumors. Trends Mol Med 14: 199-209, 2008

20. Mårtensson A, Oberg A, Jung A, et al: Beta-catenin expression in relation to genetic instability and prognosis in colorectal cancer. Oncol Rep 17: 447-452, 2007.
21. Chen Z, He X, Jia M, et al: Beta-catenin overexpression in the nucleus predicts progress disease and unfavourable survival in colorectal cancer: a meta-analysis. PloS One 8: e63854, 2013.

22. Hörkkö TT, Klintrup K, Mäkinen JM, et al: Budding invasive margin and prognosis in colorectal cancer - no direct association with beta-catenin expression. Eur J Cancer 42: 964-971, 2006.

23. Roca F, Mauro LV, Morandi A, et al: Prognostic value of E-cadherin, beta-catenin, MMPs (7 and 9), and TIMPs $(1$ and 2$)$ in patients with colorectal carcinoma. J Surg Oncol 93: 151-160, 2006

24. Lee SJ, Choi SY, Kim WJ, et al: Combined aberrant expression of E-cadherin and S100A4, but not beta-catenin is associated with disease-free survival and overall survival in colorectal cancer patients. Diagn Pathol 8: 99, 2013.

25. Wangefjord S, Brändstedt J, Lindquist KE, et al: Associations of beta-catenin alterations and MSI screening status with expression of key cell cycle regulating proteins and survival from colorectal cancer. Diagn Pathol 8: 10, 2013. 